\title{
Bir Ölçek Geliştirme Çalışması, Tıp Eğitimine Yönelik Tutum Ölçeği: Güvenirlik ve Geçerlik Çalışması
}

\author{
A Scale Development Study, Attitude Scale Towards Medical \\ Education: A Study OnReliability and Validity
}

\author{
Hüseyin SELVİ*, İbrahim BAŞHAN**
}

Öz: Bu çalışmada tıp fakültesi öğrencilerinin tıp eğitimine ilişkin tutumlarının güvenilir ve geçerli bir şekilde ortaya konabilmesi amacıyla bir ölçme aracı geliştirilmesi amaçlanmıştır. Temel araştırma niteliğinde olan bu çalışma bir ölçek geliştirme çalışması olup, 41 maddelik ölçek deneme formu kullanılarak toplam 552 öğrenciden elde edilen veriler üzerinden yürütülmüştür. Elde edilen verilerin analizinde; güvenirlik için Cronbach alfa katsayısı, yapı geçerliği için Açımlayıcı Faktör Analizi ve Doğrulayıcı Faktör Analizi, geçerliğe ek kanıt sağlamak için ise alt ve üst gruplar arasında $t$ testiuygulanmıştır. Verilerin faktör analizine uygunluğu için ise Bartlett testi ve Kaiser-Meyer-Olkin (KMO) testi yapılmıştır. 41 madde için hesaplanan madde-toplam puan arası ilişkilerin 0,297 ile 0,719 arasında değiştiği görülmüştür. Gerçekleştirilen AFA sonucunda birden fazla bileşene yük veren, herhangi bir bileşen altında yer almayan ve ortak varyans (communality) değerleri 0,32 altında yer alan toplam 13 madde ölçekten çıkarılmıştır. AFA sonucunda ve promax döndürme işlemi yapıldıktan sonra özdeğeri 1,00'den büyük 6 bileşen bulunmuştur. Açıklanan toplam varyans oranı \%62.237'dir. Doğrulayıcı faktör analizinde hesaplanan uyum indeksleri ise; RMSEA=0,067; CFI= 0.97; GFI= 0.84; $\mathrm{AGFI}=0.80 ; \mathrm{RMR}=0.069$ şeklinde elde edilmiştir. Elde edilen bulgular, model uyumunun sağlandığını göstermektedir. Ölçeğin bütününe yönelik hesaplanan alfa güvenirliği ise 0.933 olarak bulunmuştur. Buna ek olarak alt bileşenlere ilişkin elde edilen alfa güvenirlik değerleri sırasıyla 0,$85 ; 0,76 ; 0,81 ; 0,82 ; 0,80$ ve 0,72 olarak hesaplanmıştır. Elde edilen bulgulardan ölçeğin hekim adaylarının tıp eğitimine yönelik tutumlarını güvenilir ve geçerli bir şekilde ortaya koyabileceği düşünülmektedir.

Anahtar Kelimeler: Tutum ölçeği, tıp eğitimine yönelik tutum, güvenirlik, geçerlik

\begin{abstract}
In this study, it was aimed to develop a measurement tool in order to reveal the attitudes of medical students towards medical education in a reliable and valid manner. This scale development study is a basic researchwhich is based on data obtained from 552 students using a 41-item scale trial form.In the analysis of the data obtained; Cronbach alpha coefficient was used for reliability, Exploratory Factor Analysis and Confirmatory Factor Analysis for construct validity and t-test for lower-upper groups was used to provide additional evidence for validity. Bartlett test and Kaiser-Meyer-Olkin (KMO) test results were taken into account for the suitability of the data for factor analysis. The item-total score correlations calculated on 41 itemsranged between 0.297 and 0.719. As a result of the EFA, 13 items were excluded in the scale, which were loading to more than one component, not under any component, and the communality values below 0.32 . After EFA and promax rotation 6 components were found which's eigenvalue was more than 1.00 . The total variance rate explained is $62.237 \%$. Adaptation indexes calculated by confirmatory factor analysis were RMSEA $=0.067$; CFI $=0.97$; GF1 $=0.84$; $\mathrm{AGFI}=0.80$; $\mathrm{RMR}=0.069$. These values show that the model compatibility was achieved. The alpha reliability of the whole scale was calculated as 0.933. In addition, the alpha reliability values obtained for the subcomponents were calculated respectively as $0.85 ; 0.76 ; 0.81 ; 0.82 ; 0.80$ and 0.72 . It was thought that the results of the scale could be used to reveal the attitudes of medical candidates towards medical educationin a reliable and valid way.
\end{abstract}

Keywords: Attitude scale, attitude towards medical education, reliability, validity

\footnotetext{
* Dr. Öğretim Üyesi, Sorumlu Yazar, Mersin Üniversitesi, Tıp Fakültesi, Mersin-Türkiye, ORCİD: 0000-0002-35130003, e-posta: hsyn_selvi@yahoo.com.tr

** Dr. Öğretim Üyesi, Mersin Üniversitesi, Tıp Fakültesi, Mersin-Türkiye, ORCID: 0000-0002-0034-2727, e-posta: ibashan@yahoo.com
} 


\section{Giriş}

Tutumlar yaşantı ve deneyimler sonucu oluşan ve birey davranışlarına yön veren önemli psikolojik değişkenlerden biridir. Allport (1935) tutum kavramını, bireylerin yaşantı ve deneyimleri sonucu oluşan, ilgili olduğu bütün obje ve durumlara karşı bireyin davranışları üzerinde yönlendirici ya da dinamik bir etkileme gücüne sahip duygusal ve zihinsel hazırlık durumu olarak açıklamaktadır. Diğer ifadeyle tutumlar; insan, kurum, özel obje ya da durumlara karşı pozitif ya da negatif yönde tepki verme eğilimi olup, insan davranışlarının başlangıç noktalarından biri olarak kabul edilmekte ve insan davranışlarının belirleyicileri arasında yer almaktadır (Aiken, 2000; Arkonaç, 2011). Tutumlar günümüzde bireylerin davranışlarını ve sosyal algılarını belirleyen en önemli psikolojik özelliklerden biridir (Alıcı, 2013).

Tutumlar öğrenilebilir bir nitelik sergilemektedir. Üniversiteler gibi meslek eğitimi veren çeşitli kurumlarda dageçirilen çeşitli yaşantılar sonucu gerek kurumun kendisine gerekse burada verilen eğitime, derslere, eğitmenlere vb. yönelik olumlu ya da olumsuz kutupta gelişebilmektedir. $\mathrm{Bu}$ da verilen eğitimin niteliğini ve bireylerin akademik başarılarını etkileyebilmektedir. Yoğun ve kapsamlı eğitimlerde bireylerin akademik başarıları üzerinde bu tutumların etkisi daha da belirginleşmektedir. Tıp eğitimi de bu yoğun ve kapsamlı eğitimlere örnek olarak verilebilir.Bilindiği üzere hekimlik, geçmişten günümüze hemen her toplum için saygın bir meslek olarak kabul edilmekte ve bu da hekimlik mesleğine olan ilgiliyi sürekli arttırmaktadır. Ancak tıp eğitimi, doğrudan insan sağlı̆̆ ve hayatına yönelik bilgi ve becerilerin kazanılmasını içerdiğinden hekim adaylarının bu eğitimi başarıyla tamamlayabilmeleri için yoğun bir özveriyle çalışmaları gerekmektedir. $\mathrm{Bu}$ eğitiminin yoğunluğu ve güçlüğü düşünüldüğünde ise eğitim süreci içinde hekim adaylarının fakültelerine, tıp eğitimine, hekimlik mesleğine vb. ilişkin tutumları olumsuz kutba kayabilmekte bu da davranışa dönüşerek bireylerin gerek öğrencilik hayatlarında akademik başarılarını gerekse meslek hayatlarında üretecekleri sağlık hizmetinin niteliğini etkileyebilmektedir. Hekim adaylarının meslek hayatlarının önemli bir bölümünü eğitim için tıp fakültelerinde geçirdikleri düşünüldügünde bireylerin burada almış oldukları eğitime (tıp eğitimine) yönelik geliştirdikleri tutumları, akademik başarı ve üretecekleri sağlık hizmetinin niteliği açısından önemlidir.

Yapılan araştırmalar öğrenme sürecinde bireylerin tutum geliştirmesinin ve bu tutumların değiştirilebilmesinin olanaklı olduğunu göstermiştir. Buna ek olarak bireylerin almış oldukları eğitime ve bu eğitimi aldıkları kurumlara yönelik tutumlarının ise akademik yaşantıları üzerinde olumlu ya da olumsuz etki gösterebilmektedir (Gül, 2004). Alıc1 (2013), eğitim aldığı kurumu sevmeyen, derslere gitmekten hoşlanmayan, nefret eden, derslerden kaçma davranışları sergileyen bir öğrencinin almakta olduğu eğitim içindeki akademik başarısı ile derslere severek katılan, derslere gitmekten zevk alan ve aldığ eğitimin önemine inanan bir öğrencinin almakta olduğu eğitim içindeki akademik başarısının aynı olmasının beklenemeyeceğini ifade etmektedir. Alıcı (2013) buna ek olarak bireylerin aldıkları eğitime, eğitim aldıkları kurumlara, derslere vb. yönelik tutumlarının saptanmasının özellikle akademik başarıyı etkileyen faktörler başta olmak üzere, öğrenciyle ilgili pek çok sorunun nedenlerinin belirlenmesine ve çözüm yollarının ortaya konmasına önemli katkı sağlayacağını belirtmektedir. $\mathrm{Bu}$ nedenle tıp eğitiminin ve hekim adaylarının mevcut sorunlarının saptanması ve giderilebilmesi, öğrencilerin akademik başarılarının ve üretilecek sağlık hizmetlerinin niteliğinin arttırılabilmesi adına hekim adaylarının tıp eğitimi ve tıp eğitimi içinde yer alan öğelere ilişkin tutumlarının güvenilir ve geçerli şekilde ortaya konması önemlidir.

Yapılan alanyazın incelemesinde bu ve benzer amaçlarla geliştirilen ölçeklere rastlanmıştır. Örneğin, Batı ve Bümen (2006) hekim adaylarının hekimlik mesleğine yönelik tutumlarının ölçülmesine yönelik 'Hekimlik Mesleğine Yönelik Tutum Ölçeği'ni geliştirmişlerdir. Ölçek, 24 maddeden oluşan ve 5 dereceli puanlanan bir ölçektir. Yapılan açımlayıcı faktör analizi ölçeğinin 'isteklilik', 'yardımcı olma' ve 'mesleğe adanmışlık' olmak üzere üç alt boyuttan oluştuğunu ortaya koymuştur. 'İsteklilik' alt boyutu onbeş, 'yardımc1 olma' alt boyutu beş ve 'mesleğe adanmışlık' alt boyutu ise dört maddeden oluşmaktadır. Ölçeğin alfa güvenirliği 'İsteklilik' alt boyutu için 0,95 ; 'yardımcı olma' alt boyutu için 0,84 ; 'mesleğe adanmışlık' alt boyutu için 0,82 ; ölçeğin geneli için ise 0,95 olarak saptanmıştır. Her 
bir boyutun açıkladı̆̆ hesaplanmıştır. Üç boyutun açıkladığı toplam varyans ise 48,161 olarak saptanmıştır. Yapılan doğrulayıcı faktör analizi sonucunda ise RMSEA değeri 0,075; RMR değeri 0,05 ve CFI değeri 0,98 olarak hesaplanmıştır.

Alanyazında benzer amaçlarla Torun, Dinçer, Öztaş, Demir ve Sanisoğlu (2018) tarafından tıp fakültesi öğrencilerinin hasta güveliği kültürüne ilişkin; Özcan, Bütün ve Gülcü (2016) tarafından mezuniyet öncesi tıbbi biyokimya eğitimine ilişkin tutumları ortaya koymak amacıyla geliştirilen ölçeklerde bulunmaktadır.Diğer taraftan yapılan alanyazın incelemesinde farklı örneklemler üzerinde geliştirilen ve öğrencilerin okula yönelik tutumları ölçmeyi amaçlayan ölçeklere de rastlanmıştır. Örneğin Alıcı (2013), lise öğrencilerinin okula yönelik tutumlarını saptayabilmek amacıyla 'okula yönelik tutum ölçeği'ni geliştirmiştir. Ölçek, 20 maddeden oluşan ve 5 dereceli puanlanan Likert tipi bir ölçektir. Yapılan açımlayıcı faktör analizi ölçeğinin 'kişisel gelişimin engeli olarak okul', 'kişisel gelişimin destekleyicisi olarak okul' ve 'özlenen bir varlık olarak okul' olmak üzere üç alt bileşenden ve tek boyuttan oluştuğunu ortaya koymuştur. 'Kişisel gelişimin engeli olarak okul' bileşeni sekiz, 'kişisel gelişimin destekleyicisi olarak okul' bileşeni sekiz ve 'özlenen bir varlık olarak okul' bileşeni ise dört maddeden oluşmaktadır. Ölç̧eğin alfa güvenirliği 'isteklilik' alt boyutu için 0,87 ; 'yardımcı olma' alt boyutu için 0,81 'mesleğe adanmışlık' alt boyutu için 0,78; ölçeğin geneli için ise 0,907 olarak saptanmıştır. Her bir boyutun açıkladığı toplam varyans sırasıyla, \%39,589; $\% 8,400$ ve \%6,152 olarak hesaplanmıştır. Üç boyutun açıkladığı toplam varyans ise 54,141 olarak saptanmıştır. Faktörlere ilişkin özdeğerler ise sırasıyla, \%13,774; \%2,164 ve \%1,799 olarak belirlenmiştir. Ölçeğin 12 maddesi olumlu, 8 maddesi ise olumsuz puanlanmaktadır. Yapılan doğrulayıcı faktör analizi sonucunda ise RMSEA değeri 0,056; RMR değeri 0,088 ve CFI değeri 0,98; GFI değeri 0,92 ve AGFI değeri ise 0,90 olarak hesaplanmıştır.

Yurtdışı alanyazınında ise; hekimlere ve birinci basamak sağlık hizmetlerine yönelik tutumların ölçülebilmesi amacıyla (Hulka, Cassel, Zyzanski ve Thompson, 1970); tıp fakültesi öğrencilerinin hekimlik mesleğine yönelik tutumların ölçülebilmesi amacıyla (Smits ve Verbeek, 2015); tıp fakültesi öğrencilerinin araştırma ve algılanan engellere yönelik tutumların ölçülebilmesi amaciyla (Althubaiti, Al Muqbil ve Al Buraikan, 2017) ve Tıp öğrencilerinin iletişim becerilerini öğrenmeye yönelik tutumların ölçülebilmesi amacıyla (Haveri, Sebastian ve Nath, 2016) geliştirilen ölçeklere rastlanmıştır.

Yapılan alanyazın incelemesi hekim adaylarının tıp eğitimine yönelik tutumlarını saptamak amacıyla geliştirilen bir ölçme aracının bulunmadığını göstermiştir.Bu nedenle bu çalışmada hekim adaylarının tıp eğitimine ilişkin tutumlarının güvenilir ve geçerli bir şekilde ortaya konabilmesi amacıyla bir ölçme aracı geliştirilmesi amaçlanmıştır. Geliştirilen ölçeğin alanyazında bulunan bu eksikliği gidermesi beklenmektedir. Ölçeğin uygulanmasıyla elde edilecek verilerin tıp fakültesi öğrencilerinin akademik başarılarını etkileyen değişkenler başta olmak üzere, eğitim sürecinde karşılaşılan pek çok sorunun nedeninin saptanması, olası çözüm yollarının tartışılması ve oluşabilecek yeni sorunların önlenmesi çalışmalarına katkı sağlayacağı düşünülmektedir.

\section{Yöntem}

$\mathrm{Bu}$ çalışmada tıp fakültesi öğrencilerinin tıp eğitimine ilişkin tutumlarını güvenilir ve geçerli şekilde ortaya koyan bir ölçme aracı geliştirmek amaçlandığından, çalışmanın temel araştırma niteliğinde olduğu söylenebilir. Çalışma için Mersin Üniversitesi, sosyal ve beşeri bilimler etik kurulundan 27.03.2019 tarih ve 20 sayılı kararla etik kurul onayı alınmıştır.

\section{Örneklem/çalışma grubu}

Çalışma kapsamında elde edilen veriler, Mersin Üniversitesi Tıp Fakültesinde öğrenim görmekte olan toplam 552 öğrenciden elde edilmiştir. Çalışmaya katılan öğrencilerin 116's1 (\%21) 1. sinif, 98'i (\%17.8) 2. sinif, 109'u (\%19.7) 3. sinif, 115'i (\%20.8) 4. sinif, 58'i (10.5) 5. sınıf ve 56's1 (\%10.1) 6. sınıf öğrencisidir. Öğrencilerin 306's1 (\%55.4) erkek, 246's1 (\%44.6) ise kadındır. 


\section{Verilerin toplanması}

Ölçme Aracı.Öğrencilerinin tıp eğitimine ilişkin tutumlarını ortaya koymak ve ölçeğin deneme formunda yer alacak maddeleri saptayabilmek amacıyla; alanyazın taraması yapılmış ve benzer amaçlarla geliştirilmiş ölçekler incelenmiştir. Buna ek olarak tıp fakültesinde öğrenim görmekte olan dönem 1'den dönem 6'ya kadar her dönemden 10'ar öğrenci olmak üzere toplam 60 öğrenciden tıp eğitimine ilişkin duygu ve düşüncelerini belirten bir kompozisyon yazmaları istenmiştir. Yapılan alanyazın incelemesi, benzer amaçlarla geliştirilen ölçekler ve öğrencilerin yazmış oldukları kompozisyonlardan elde edilen veriler birleştirilmiş ve tıp fakültesi öğrencilerinin tıp eğitimine ilişkin tutumlarının davranışsal göstergesi olabileceği öngörülen 65 maddelik taslak bir form oluşturulmuştur. İlgili taslak form ölçme ve değerlendirme alanında 1 , temel tıp bilimleri alanında 2, cerrahi tıp bilimleri alanında 1 ve dâhili tıp bilimleri alanında 1 uzman tarafindan incelenmiştir. Yapılan incelemeler sonucunda amaca uygun olmadığı saptanan maddeler formdan çıkarılmıș ve geriye kalan 41 madde üzerinden ölçeğin deneme formu oluşturulmuştur. Deneme formunda yer alan maddeler; 22 olumlu ve 19 olumsuz ifadeden oluşmaktadır. Formda yer alan her bir madde, "Kesinlikle Katılmıyorum", "Katılmıyorum", "Kararsızım", "Katıliyorum" ve "Tamamen Katılıyorum" şeklinde 5'li Likert tipi dereceleme ölçeği yardımıyla puanlanmıştır. Oluşturulan taslak form Mersin üniversitesi Tıp Fakültesinde öğrenim görmekte olan toplam 552 tıp fakültesi öğrencisine uygulanmıştır.

\section{İşlem}

Tıp eğitimine yönelik tutum ölçeğinin verileri, yazarlar tarafindan ölçek deneme formu kullanılarak tıp fakültesi öğrencileri üzerinden toplanmıştır. Daha sonra elde edilen veriler, bilgisayar ortamına aktarılmış ve öncelikle olası hatalı veri girişlerini saptamak ve gidermek adına bütün değişkenler için veri kalite kontrolü yapılmıştır. Bir sonraki aşamada ise olumsuz ifade içeren maddelerin ters puanlama işlemi yapılmış ve uçdeğer analizine geçilmiştir. Yapılan uçdeğer analizi sonrasında 12 katılımcıya ilișkin verinin uç değer vermesi nedeniyle bu kișilerin analiz dışında tutulması kararlaştırılmıştır. Kalan 540 katılımcıya ilişkin elde edilen veriler üzerinden yapılan kayıp değer analizi kayıp değer dağılımının seçkisiz yapıda olduğunu (Little's MCAR Test ki-kare: $1430.80 \mathrm{p}<0.05$, Missing at Random) göstermiş ve bu nedenle kayıp değerlerin yerine beklenti maksimizasyonu yöntemiyle değer ataması yapılarak analizlere devam edilmiştir.

\section{Verilerin analizi}

Tıp eğitimine yönelik tutum ölçeğinin madde analizlerinde ise madde-toplam puanı arasındaki ilişki ise Pearson korelâsyon katsayısıyla incelenmiş ve analiz sonrasında toplam puanla 0.20 ve altında korelâsyon veren maddeler taslak formdan çıkarılmıştır (Tavşancıl, 2006). Bir sonraki aşamada ölçeğin faktör yapısı açımlayıcı faktör analizi (AFA) kullanılarak incelenmiştir. Verilerin faktör analizine uygunluğu için Bartlett testi ve Kaiser-Meyer-Olkin (KMO) testi sonuçları dikkate alınmıştır (Tavşancıl, 2006). Ölçeğin güvenirliği ise Cronbach Alfa güvenirlik katsayısıyla incelenmiştir.Analizler sırasında elde edilen madde-ölçek korelâsyonlarının ve alfa katsayısının yüksek olması faktörler/bileşenler arasındaki ilişkinin yüksek olduğunu düşündürmüş ve bu nedenle eğik döndürme yöntemlerinden promax döndürmenin (Kappa:4) yapılması kararlaştırılmıştır (Erkuş, 2003; Tatlıdil, 1992). Promax döndürmede özdeğeri 1.00 'den büyük faktörler üzerinde işlem yapılmış, madde faktör yükü alt sınırı 0.32 olarak belirlenmiş ve birden fazla faktöre yük veren maddelerin yük değerleri arasındaki farkın en az 0.10 olmasına dikkat edilmiştir (Tavşanc1l, 2006; Tabachnick \& Fidel, 2001; Alıc1, 2013). Promax döndürme yöntemi kullanılarak gerçekleştirilen AFA sonucunda belirlenen yapının geçerliğine kanıt sağlamak ve gözlenen yapının verilerle ne derece uyumlu olduğunu ortaya koymak amacıyla aynı fakültede öğrenim görmekte olan 311 kişilik farklı bir örneklemden elde edilen (181 erkek $(\% 58.19)$ ve 130 kadın $(\% 41,81))$ veriler üzerinden doğrulayıcı faktör analizi (DFA) çalışması yapılmıştır. DFA'da modelin geçerliğini değerlendirmek amacıyla Ki-Kare Uyum Testi, Yaklaşık Hataların Ortalama Karekökü (RMSEA), Karşılaştırmalı Uyum İndeksi 
(CFI), İyilik Uyum İndeksi (GFI), Düzeltilmiş İyilik Uyum İndeksi (AGFI) ve Artık Ortalamaların Karekökü (RMR) değerleri incelenmiştir (Kline, 2005). Buna ek olarak ölçeğin geçerliğine ek kanıt sağlamak amacıyla, ölçek toplam puanlarının alt $\% 27$ ve üst $\% 27$ grup ortalamaları arası fark bağımsız gruplar $t$ testi ile incelenmiştir. Ölçekten elde edilen toplam puana ilişkin dağılım üzerinden hesaplanan basıklık ve çarpıklık değerleri sırasıyla alt grup için 0,412 ve 0,380 ; üst grup için 0,380 ve 0,350 ; toplam grup için ise 0,393 ve 0,351 şeklinde bulunmuştur. Şenocak (2014) çarpıklık değerinin 1.00 'den, basıklık değerinin de 2.00 'den küçük olması durumunda dağılımın normal kabul edilebileceğini ifade etmektedir. Bu nedenle ölçek toplam puanına ilişkin dağılımın normal olduğu kabul edilmiştir.

\section{Bulgular}

Madde analizi

Madde-Toplam ölçek puanı arasındaki korelâsyona dayalı madde analizi çalışması ölçek toplam puanıyla 0.20 'nin altında korelâsyon veren madde bulunmadığını göstermiştir.

\section{Ölçeğin faktör yapısının incelenmesi}

Madde analizi sonrası 41 maddeden oluşan ölçek deneme formuna ilişkin verinin faktör analizine uygunluğu için hesaplanan KMO değeri 0.925 olarak bulunmuş ve Barlett testi sonucunda hesaplanan ki-kare istatistiğinin de manidar olduğu (ki-kare $=7258.59, \mathrm{p}<0,01)$ gözlenmiştir. Bu iki bulgu sonucunda veri setinin faktör analizine uygun olduğunu kanaatine varılmıştır.Tıp eğitimine yönelik tutum ölçeğinin deneme formuna ilişkin 41 madde üzerinden döndürme öncesi hesaplanan madde-toplam ölçek puanı korelâsyonları ve faktör analizi sonuçları Tablo 1'de sunulmuştur. Buna ek olarak özdeğerlere ilişkin saçılım grafiğgi ise Şekil 1 'de sunulmuştur.

Tablo 1.

T1p Eğitimine Yönelik Tutum Ölçeğinin Deneme Formuna İlişkin Döndürme Öncesi Faktör Analizi Sonuçları

\begin{tabular}{|c|c|c|c|c|c|c|c|}
\hline \multirow{2}{*}{ Madde No } & \multirow{2}{*}{$\begin{array}{l}\text { Ortak Varyans } \\
\text { (Communality) }\end{array}$} & \multirow[t]{2}{*}{ Madde-Ölçek Korelâsyonu } & \multicolumn{5}{|c|}{ Faktör Yükleri } \\
\hline & & & 1 & 2 & 3 & 4 & 5 \\
\hline Madde 36 & 0,697 & 0,716 & ,733 & & & & \\
\hline Madde 28 & 0,714 & 0,719 & ,722 & & & & \\
\hline Madde 29 & 0,640 & 0,691 & ,702 & & & & \\
\hline Madde 17 & 0,631 & 0,687 & 691 & & &,- 315 & \\
\hline Madde 18 & 0,624 & 0,681 & 688 & & & & \\
\hline Madde 2 & 0,652 & 0,682 & 688 & & & & \\
\hline Madde 19 & 0,659 & 0,663 & 668 & & & & \\
\hline Madde 3 & 0,648 & 0,661 & 660 & & & & \\
\hline Madde 37 & 0,595 & 0,605 & 658 & & & & \\
\hline Madde 40 & 0,662 & 0,656 & 651 & & & ,384 & \\
\hline Madde 25 & 0,561 & 0,648 & 638 & & & & \\
\hline Madde 5 & 0,739 & 0,636 & ,630 & & & & 414 \\
\hline Madde 20 & 0,712 & 0,636 & 623 & & & & \\
\hline Madde 34 & 0,589 & 0,605 & ,596 & & & & \\
\hline Madde 38 & 0,602 & 0,532 & ,592 & & & & \\
\hline Madde 35 & 0,613 & 0,593 & ,589 &,- 358 & & & \\
\hline Madde 10 & 0,706 & 0,612 & ,587 &,- 381 & & & \\
\hline Madde 30 & 0,502 & 0,577 & ,576 & & & & \\
\hline Madde 33 & 0,576 & 0,575 & ,569 & & & & \\
\hline Madde 15 & 0,721 & 0,553 & ,557 & &,- 398 & & \\
\hline Madde 4 & 0,567 & 0,559 & ,554 & & & & \\
\hline Madde 9 & 0,628 & 0,567 & ,547 &,- 377 & & & \\
\hline
\end{tabular}




\begin{tabular}{lllllll}
\hline Madde 1 & 0,625 & 0,532 &, 542 &, 418 & & \\
Madde 41 & 0,515 & 0,554 &, 542 & & & \\
Madde 39 & 0,653 & 0,547 &, 535 & &, 321 &, 316 \\
Madde 16 & 0,687 & 0,524 &, 530 & & &,- 303 \\
Madde 14 & 0,580 & 0,527 &, 521 & &, 301 & \\
Madde 21 & 0,635 & 0,546 &, 520 & & & \\
Madde 7 & 0,660 & 0,514 &, 512 & &, 490 & \\
Madde 6 & 0,559 & 0,526 &, 511 & & & \\
Madde 26 & 0,426 & 0,531 &, 503 & & & \\
Madde 11 & 0,652 & 0,526 &, 496 &,- 319 & & \multirow{2}{*}{, 342} \\
Madde 8 & 0,487 & 0,516 &, 479 & & & \\
Madde 27 & 0,588 & 0,495 &, 476 &,- 430 & & \\
Madde 22 & 0,414 & 0,510 &, 465 &,- 304 & & \\
Madde 32 & 0,667 & 0,480 &, 458 &, 321 & & \\
Madde 12 & 0,535 & 0,390 &, 377 & & & \\
Madde 24 & 0,559 & 0,299 & & & & \\
Madde 31 & 0,543 & 0,297 & &, 358 & & \multirow{2}{*}{, 308} \\
Madde 13 & 0,588 & 0,390 &, 377 & &, 470 & \\
Madde 23 & 0,556 & 0,395 &, 390 & &, 394 & \\
\hline
\end{tabular}

$* * \mathrm{p}<0.01$

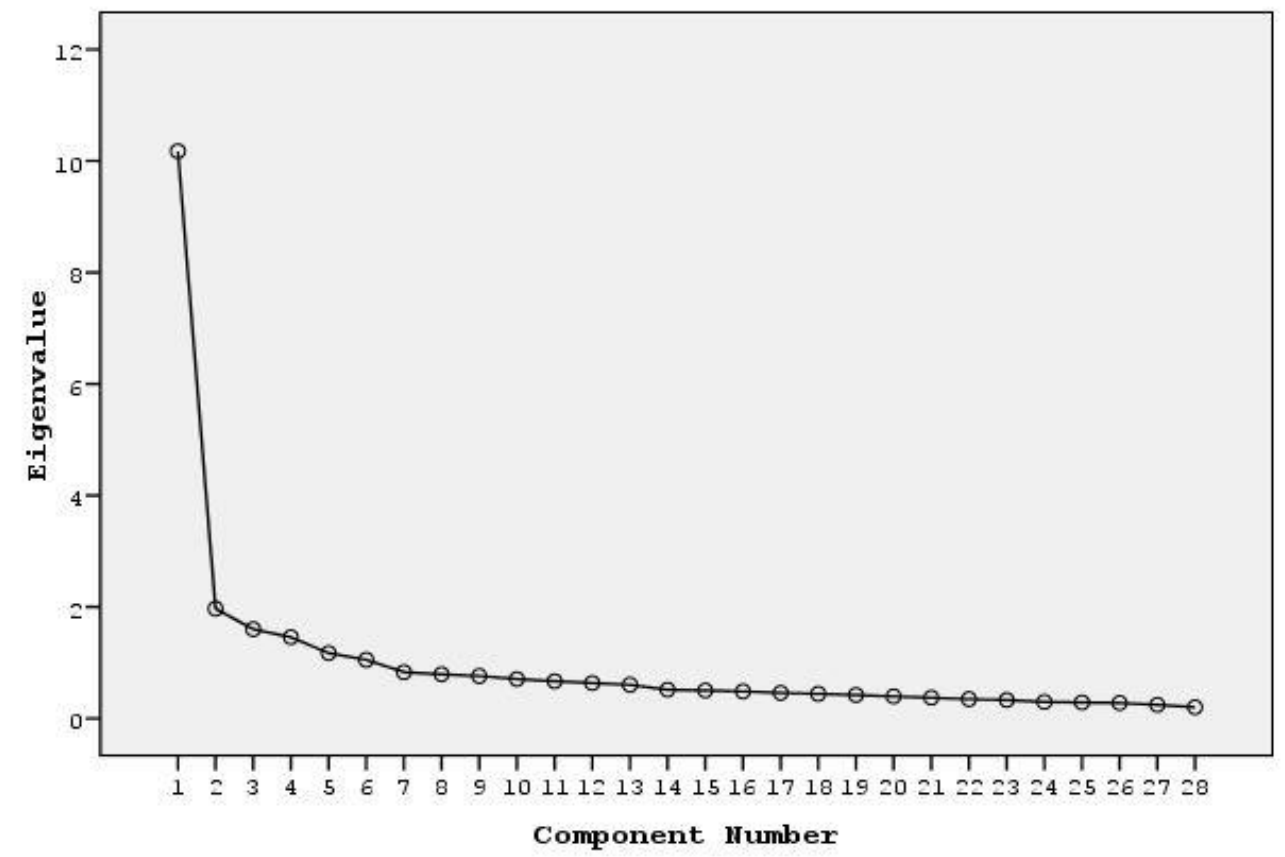

Şekil 1. Özdeğerler grafiği (saçılım diyagramı)

Tablo 1 ve Şekil 1 incelendiğinde 41 madde üzerinden hesaplanan madde-toplam ölçek puanı korelâsyonlarının 0,297 ile 0,719 arasında değiştiği ve maddelerin ağırlıklı olarak ilk faktör altında toplandığı görülmektedir. Gerçekleștirilen AFA analizlerinde birden fazla bileşene yük veren, herhangi bir bileșen altında yer almayan ve ortak varyans (communality) değerleri 0,32 altında yer alan toplam 13 madde ölçekten çıkarılmış ve geriye kalan 28 madde üzerinden AFA tekrarlanmıştır. AFA sonucunda ve promax döndürme işlemi yapıldıktan sonra özdeğeri 1,00 'den büyük 6 bileşen bulunmuştur. Bulunan bu yapının açıkladığı toplam varyans oranı $\% 62.237$ 'dir. Her bileşenin açıkladığı varyans oranı sırasıyla, \%36.342; \%7,035; \%5,715; $\% 5,203 ; \% 4,189$ ve $\% 3,754$ şeklindedir. Her bir bileşene ilişkin hesaplanan özdeğerler ise sirasiyla, 10,$176 ; 1,970 ; 1,600 ; 1,457 ; 1,173$ ve 1,051 şeklindedir. AFA sonucunda ve promax 
Bir ölçek geliştirme çalışması, tıp eğitimine yönelik tutum ölçeği: güvenirlik ve geçerlik çalışması

döndürme sonrasında elde edilen ortak varyans (communality) değerleri, madde ölçek korelâsyonları ve faktör yük değerleri ise Tablo 2'de sunulmuştur.

Tablo 2.

Tıp Eğitimine Yönelik Tutum Ölçeğinin Deneme Formuna Ilişkin Döndürme Sonrası AFA Sonuçları

\begin{tabular}{|c|c|c|c|c|c|c|c|c|c|}
\hline Mad. & Maddeler & Communa & Madde- & Fak & Yük & & & & \\
\hline No & & lity & Ölçek Kor. & 1 & 2 & 3 & 4 & 5 & 6 \\
\hline 15 & Tıbbi konular hiç ilgimi çekmiyor. & & $0,541 * *$ &, 81 & & & & & \\
\hline 38 & $\begin{array}{l}\text { T1p eğitimi kelimesi bile beni } \\
\text { huzursuz etmeve yetivor. }\end{array}$ & 0,589 & $0,601 * *$ & $\begin{array}{l}4 \\
72 \\
7\end{array}$ & & & & & \\
\hline 29 & $\begin{array}{l}\text { Fakülteye her gideceğimde içime bir } \\
\text { sıkıntı çöküyor. }\end{array}$ & 0,635 & $0,716^{* *}$ & $\begin{array}{l}, 61 \\
4\end{array}$ & & & & & \\
\hline 28 & Tıp eğitimi bana göre değil. & 0,665 & $0,713 * *$ & $\begin{array}{l}, 59 \\
6\end{array}$ & & & & & \\
\hline 18 & $\begin{array}{l}\text { Kendimi bu eğitimin bir parçasıymış } \\
\text { gibi hissetmiyorum. }\end{array}$ & 0,629 & $0,714 * *$ & $\begin{array}{l}, 57 \\
3\end{array}$ & & & & & \\
\hline 30 & $\begin{array}{l}\text { Tibbi konuları tartışmaktan zevk } \\
\text { alıyorum. }\end{array}$ & 0,484 & $0,564 * *$ & $\begin{array}{l}, 56 \\
8\end{array}$ & & & & & \\
\hline 17 & $\begin{array}{l}\text { Bu eğitim için harcadığım zamana } \\
\text { acıyorum. }\end{array}$ & 0,618 & $0,724 * *$ & $\begin{array}{l}, 52 \\
2\end{array}$ & & & & & \\
\hline 27 & $\begin{array}{l}\text { T1p eğitimi hekimlik konusundaki } \\
\text { beklentilerimi karș1lamıor. }\end{array}$ & 0.625 & $0,522 * *$ & & $\begin{array}{l}, 75 \\
6\end{array}$ & & & & \\
\hline 9 & $\begin{array}{l}\text { T1p eğitimi hiç de hayal ettiğim gibi } \\
\text { değilmiş. }\end{array}$ & 0,631 & $0,600 * *$ & & $\begin{array}{l}, 66 \\
6\end{array}$ & & & & \\
\hline 35 & $\begin{array}{l}\text { Tıp eğitimi, hekim olma isteğimi yok } \\
\text { ediyor. }\end{array}$ & 0,631 & $0,627 * *$ & & $\begin{array}{l}, 65 \\
3\end{array}$ & & & & \\
\hline 26 & $\begin{array}{l}\text { Bence tıp eğitimi kadar angaryalarla } \\
\text { dolu başka bir eğitim daha yok. }\end{array}$ & 0,432 & $0,547 * *$ & & $\begin{array}{l}, 55 \\
8\end{array}$ & & & & \\
\hline 8 & $\begin{array}{l}\text { Bu eğitim beni kendimden } \\
\text { uzaklaştırıyor. }\end{array}$ & 0,446 & $0,530 * *$ & & $\begin{array}{l}51 \\
6\end{array}$ & & & & \\
\hline 3 & $\begin{array}{l}\text { Bazen dersler çok ağır gelse de almış } \\
\text { olduğum eğitimi seviyorum. }\end{array}$ & 0,693 & $0,689 * *$ & & & $\begin{array}{l}, 77 \\
4\end{array}$ & & & \\
\hline 4 & $\begin{array}{l}\text { Burada öğrendiklerim beni } \\
\text { heyecanlandırıyor. }\end{array}$ & 0,567 & $0,557 * *$ & & & $\begin{array}{l}, 71 \\
4\end{array}$ & & & \\
\hline 5 & $\begin{array}{l}\text { Her şeye rağmen tekrar seçme } \\
\text { şansım olsa yine tıp seçerdim. }\end{array}$ & 0,667 & $0,625 * *$ & & & $\begin{array}{l}, 70 \\
7\end{array}$ & & & \\
\hline 2 & $\begin{array}{l}\text { Benim için tıp eğitimi eşi bulunmaz } \\
\text { bir deneyim. }\end{array}$ & 0,695 & $0,667 * *$ & & & $\begin{array}{l}, 67 \\
0\end{array}$ & & & \\
\hline 11 & $\begin{array}{l}\text { Derslerde çoğu zaman uykum } \\
\text { geliyor. }\end{array}$ & 0,676 & $0,546 * *$ & & & & $\begin{array}{l}, 76 \\
4\end{array}$ & & \\
\hline 20 & $\begin{array}{l}\text { Derslere hevesle katıldı̆̆ım } \\
\text { söylenemez. }\end{array}$ & 0,719 & $0,654 * *$ & & & & $\begin{array}{l}, 73 \\
1\end{array}$ & & \\
\hline 10 & $\begin{array}{l}\text { Dersler o kadar sıkıcı ki zaman bir } \\
\text { türlü geçmek bilmiyor. }\end{array}$ & 0,701 & $0,636 * *$ & & & & $\begin{array}{l}, 69 \\
0\end{array}$ & & \\
\hline 21 & $\begin{array}{l}\text { Yoklama almasalar derslere hiç } \\
\text { gitmem. }\end{array}$ & 0,650 & $0,550 * *$ & & & & $\begin{array}{l}, 68 \\
1\end{array}$ & & \\
\hline 39 & $\begin{array}{l}\text { Bu eğitim süresince aldığım her } \\
\text { dersten sonra kendimi daha } \\
\text { donanımlı hissediyorum. }\end{array}$ & 0,687 & $0,549 * *$ & & & & & $\begin{array}{l}, 82 \\
8\end{array}$ & \\
\hline 40 & $\begin{array}{l}\text { Fakülteye her gelişimde içimde bir } \\
\text { öğrenme isteği uyanıyor. }\end{array}$ & 0,717 & $0,666 * *$ & & & & & $\begin{array}{l}, 77 \\
5\end{array}$ & \\
\hline 37 & Tip eğitimini eğlenceli buluyorum. & 0,619 & $0,680 * *$ & & & & & $\begin{array}{l}, 59 \\
1\end{array}$ & \\
\hline 34 & $\begin{array}{l}\text { Uzak kaldığımda derslerimi } \\
\text { özlüyorum. }\end{array}$ & 0,525 & $0,607 * *$ & & & & & $\begin{array}{l}, 52 \\
7\end{array}$ & \\
\hline 41 & $\begin{array}{l}\text { T1p eğitiminde işlenen konular, insan } \\
\text { sağlığını öğrenme konusunda beni } \\
\text { daha meraklı birisi yaptı. }\end{array}$ & 0,472 & $0,550 * *$ & & & & & $\begin{array}{l}47 \\
9\end{array}$ & \\
\hline 13 & $\begin{array}{l}\text { İyi hekim olmanın yolu bence } \\
\text { nitelikli bir tıp eğitiminden geçer. }\end{array}$ & 0,726 & $0,362 * *$ & & & & & & ,874 \\
\hline
\end{tabular}




\begin{tabular}{lllll}
\hline 7 & $\begin{array}{l}\text { Tip eğitimi iyi hekim olabilmek için } \\
\text { bence bir firsat. }\end{array}$ & 0,660 & $0,484^{* *}$ &, 742 \\
$14 \quad \begin{array}{l}\text { Tip eğitimi, insanlığa hizmet } \\
\text { edebilmek için eşi bulunmaz bir } \\
\text { firsat. }\end{array}$ & $0,505^{* *}$ &, 564 \\
\hline$* * \mathrm{p}<0.01$ & 0,608 & & \\
\end{tabular}

Tablo 2 incelendiğinde; Birinci bileşende yer alan maddelerin öğrencilerin tıp eğitimine aidiyet hisleri ile ilgili durumları yansıttığ 1 ve bu nedenle 'aidiyet' bileşeni olarak adlandırılmasının uygun olacağı; İkinci bileşende yer alan maddelerin öğrencilerin tıp eğitiminden beklentileri ile ilgili durumları yansıttığı ve bu nedenle 'beklentiler' bileşeni olarak adlandırılmasının uygun olacağı; Üçüncü bileșende yer alan maddelerin öğrencilerin tıp eğitimine isteklilikleri ile ilgili durumları yansıttığı ve bu nedenle 'isteklilik' bileşeni olarak adlandırılmasının uygun olacağı; Dördüncü bileşende yer alan maddelerin öğrencilerin tıp eğitimi içinde yer alan derslere katılma ve devam istekleri ile ilgili durumları yansıttı̆̆ 1 ve bu nedenle 'devamsızlık eğilimi' bileşeni olarak adlandırılmasının uygun olacağı; Beşinci bileșende yer alan maddelerin öğrencilerin tıp eğitimine yönelik motivasyonları ile ilgili durumları yansıttı̆̆ ve bu nedenle 'motivasyon' bileșeni olarak adlandırılmasının uygun olacağı; Altıncı bileşende yer alan maddelerin öğrencilerin iyi bir hekim olabilmeleri için iyi bir tıp eğitimi almaları gerekliliğine ilişkin farkındalıklarını yansıttı̆̆ 1 ve bu nedenle 'farkındalık' bileşeni olarak adlandırılmasının uygun olacağı düşünülmüştür.

28 maddelik ölçekten alınabilecek en düşük puan 28 , en yüksek puan ise 140 'dır. 540 katılımcıya ilişkin ölçekten elde edilen en düşük puan 55, en yüksek puan ise 133 bulunmuştur. $\mathrm{Bu}$ ranjın ölçekten beklenen ranj1 yeterli düzeyde yansıttığı söylenebilir.AFA sonucunda belirlenen yapının geçerliğine kanıt sağlamak amacıyla farklı bireylerden elde edilen veriler üzerinde doğrulayıcı faktör analizi (DFA) çalışması yapılmıştır. Elde edilen model Şekil 2'de sunulmuştur.Doğrulayıcı faktör analizi ile hesaplanan uyum indeksleri, RMSEA=0,067; CFI= 0.97; $\mathrm{GFI}=0.84 ; \mathrm{AGFI}=0.80 ; \mathrm{RMR}=0.069$ şeklinde elde edilmiştir. Elde edilen bu değerler, model uyumunun sağlandığını göstermektedir. Ki-kare $=742,80(\mathrm{sd}=335)$ istatistiğinin manidar olduğu $(\mathrm{p}<0.01)$ gözlenmiştir ve ki-kare/sd =2,21 olarak hesaplanmıştır. Buradan modelin kabul edilebilir bir uyum iyiliğine sahip olduğunu söylenebilir. Nitekim alanyazında ki-kare/sd oranının 3'ün altında olması mükemmel uyumun, 5'in altında olması ise orta düzeyde uyumun; RMSEA ve RMR değerlerinin 0.05 'ten küçük veya eşit olması iyi bir uyumun, 0.05 ile 0.08 arasında olması ise yeterli bir uyumun; CFI değerinin 0.95 'ten, GFI değerinin 0.90'dan, AGFI değerinin ise 0.85 'ten büyük olması ise kabul edilebilir bir uyumun göstergesi olarak kabul edilmektedir (Kline, 2005; Şimşek, 2007; Y1lmaz ve Çelik, 2009). 


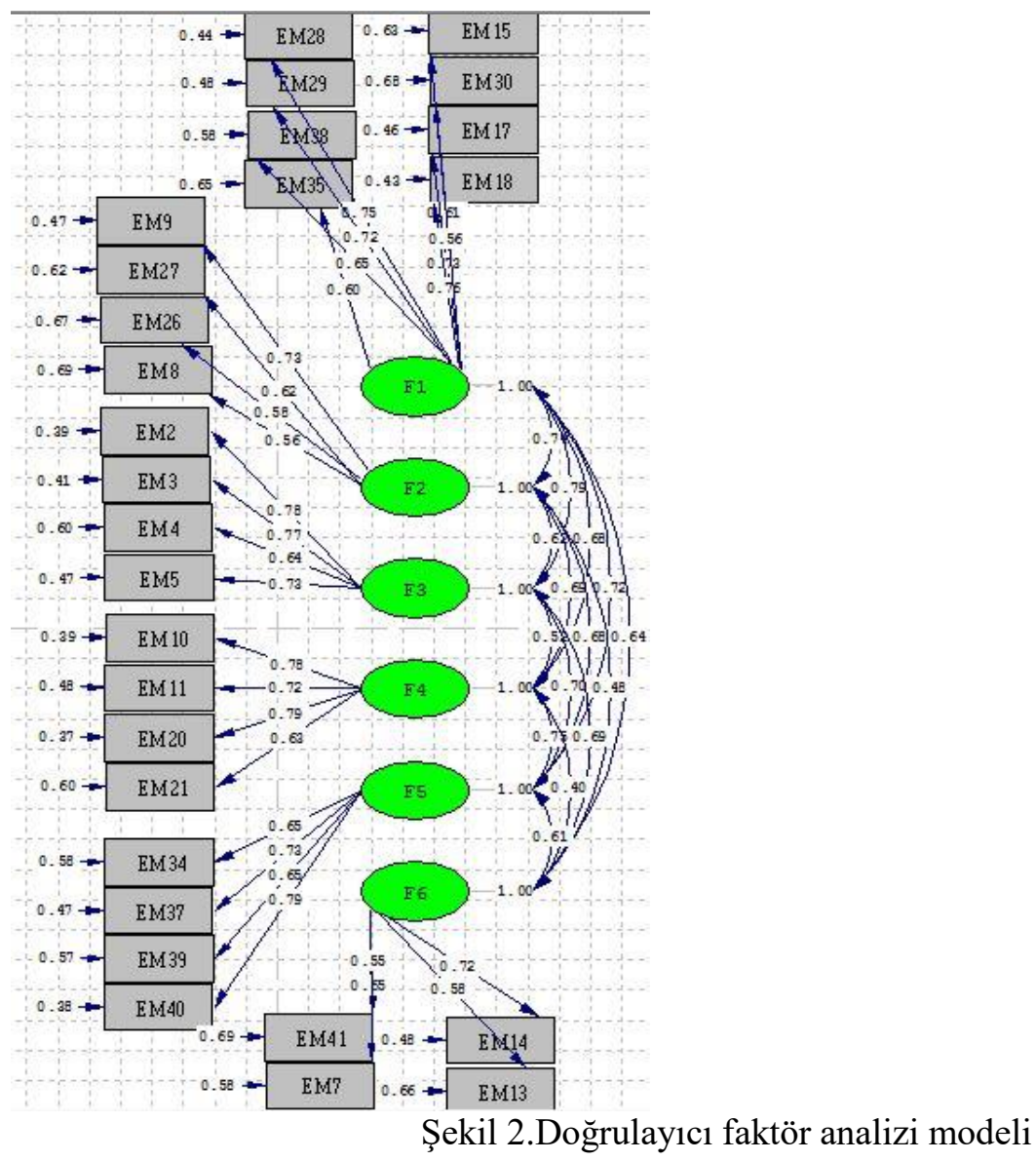

Ölçeğin Geçerliğine IIlişkin Ek Kanıt: Ölçeğin geçerliğine ek kanıt sağlamak amacıyla toplam puanları üzerinden alt $\% 27$ ve üst \%27'lik gruplar arasında anlamlı fark olup olmadığ incelenmiş ve üst \%27'lik grubun ölçek toplam puan ortalamalarının anlamlı şekilde alt \%27'lik grup ölçek toplam puan ortalamalarından yüksek olduğu gözlenmiştir. (Üst Grup $\bar{x}$ : $124,47 \pm 6,41$; Alt grup $\bar{x}: 78,83 \pm 9,53 ; \mathrm{t}:-48,040 ; \mathrm{p}<0,001)$.

\section{Ölçeğin güvenirliği}

Ölçeğin bütününe ilişkin alfa güvenirliği 0.933 olarak hesaplanmıştır. Buna ek olarak alt bileşenlere ilişkin elde edilen alfa güvenirlik değerleri sırasıyla 1 . alt bileşen için 0,$85 ; 2$. alt bileşen için 0,$76 ; 3$. alt bileşen için 0,$81 ; 4$. alt bileşen için 0,$82 ; 5$. alt bileşen için 0,80 ve 6 . alt bileşen için ise 0,72 olarak hesaplanmıştır.

\section{Tartışma, Sonuç ve Öneriler}

Hekim adaylarının tıp eğitimine yönelik tutumlarını ölçmek amacıyla gerçekleştirilen bu çalışmada 41 maddeden oluşan ölçek deneme formu, tıp fakültesinde öğrenim görmekte olan 552 öğrenciye uygulanmış, yapılan analizler 12 katılımcının uç değer verdiğini göstermiş ve bu bireyler analiz dışında tutularak geriye kalan 540 birey üzerinden güvenirlik ve geçerlik çalışmaları gerçekleştirilmiştir.

Toplam puanla 0.20 ve altında korelâsyon veren madde bulunmadığından 41 maddelik deneme formundan elde edilen veriler üzerinden ölçeğin faktör yapısı incelenmiştir. Güvenirlik katsayısının ve maddeler arası korelasonların yüksek olması, ölçeğin tek faktörlü bir yap1 sergilediğini düşündürmüş ve bu nedenle açımlayıcı faktör analizinde eğik döndürme yöntemlerinden promax döndürme kullanılmıştır. AFA sonucunda ölçeğin tek faktör ve altı bileşenden oluştuğu ve bu bileşenlerin toplam varyansın \%62.237'ni açıkladığ görülmüştür. Ortaya konan tek faktörlü ve altı bileşenli bu yapı farklı örneklemden elde edilen veriler 
üzerinde gerçekleştirilen DFA analizi sonucunda da doğrulanmıştır. Ölçek nihai formu toplam 28 maddeden oluşmaktadır ve bu maddelerin 15'i olumsuz, 13'ü ise olumlu ifade içermektedir. Ölçeğin geçerliğine ilişkin ek kanıt ortaya koymak amacıyla ölçek toplam puanları üzerinden alt ve üst \%27'lik gruplar arasında fark olup olmadığı incelenmiş ve istatistiksel açıdan anlamlı fark olduğu gözlenmiştir. Bu hususta Edwards (1957) gerek madde bazında gerekse toplam puan bazında alt ve üst gruplar arasında fark çıkmasının ölçeğin geçerliğine ilişkin kanıt sağladığını ifade etmiş ve korelâsyona dayalı analiz yerine alt-üst grup ortalamalarının test edilmesine dayalı analizin daha kolay ve pratik olduğunu ifade etmiştir. Ölçek nihai formunun güvenirlik analizi sonucunda alfa katsayısının 0,93 olduğunu bulunmuştur.

Bu sonuçlardan ölçeğin hekim adaylarının tıp eğitimine yönelik tutumlarını güvenilir ve geçerli bir şekilde yansıttığ söylenebilir.

Ölçeğin güvenirliğine ilişkin test-tekrar test yöntemi gibi farklı güvenirlik saptama yöntemlerine yönelik olarak veri toplanması ve güvenirliğinin desteklenmesi önerilebilir. Buna ek olarak ölçeğin güvenirlik ve geçerliğinin belirli zaman aralıklarıyla yeniden incelenmesi önerilebilir.

\section{Kaynaklar}

Adıgüzel, A. (2012). Okula ilişkin tutum ölçeğinin geçerlik ve güvenirlik çalışması. Elektronik Sosyal Bilimler Dergisi, 11(40), 30-45.

Allport. G. (1961). Pattern and growth in personality,Oxford: Holt, Reingart \& Winston.

Althubaiti, A., Al Muqbil, B., ve Al Buraikan, D. (2017). Assessment of medical student's attitudes towards research and perceived barriers. International Journal of Medical Students, 5(3), 95-98.

Alıc1, D. (2013). Okula yönelik tutum ölçeği'nin geliştirilmesi: Güvenirlik ve geçerlik çalışması. Eğitim ve Bilim, 38(268), 318-331.

Arkonaç, S.A. (1998). Sosyal psikoloji. İstantul: Alfa Yayım-Dağıtım.

Aiken, L. R. (2000). Psychological testing and assessment.Boston: Allyn and Bacon.

Bati, A. H. ve Bümen, N. (2006). Hekimlik mesleğine yönelik tutum ölçeğinin geliştirilmesi. Tıp Ĕ̈itimi Dünyası, 6(1), 41-50.

Edwards, A. L. (1957). Techniques of attitude scale construction. New York: AppletonCentury-Crofts.

Erkuş A. (2003). Psikometri üzerine yazılar. Ankara: Türk Psikologlar Derneği Yayınları.

Gül, G. (2004). Birey toplum eğitim ve öğretmen. Hasan Ali Yücel Eğitim Fakültesi Dergisi, l(1), 223-236.

Haveri, S.P., Sebastian, N. M. ve Nath, A. S. (2015). Attitude of medical students towards learning communication skills. International Journal of Community Medicine and Public Health, 3(1), 157-160.

Hulka, B. S., Zyzanski, S. J., Cassel, J. C. ve Thompson, S. J. (1970). Scale for the measurement of attitudes toward physicians and primary medical care. Medical Care, $8(1), 429-436$.

Kline, R. B. (2005). Principles and practice of structural equation modeling (second edition). New York: The Guilford Press.

Smits, P. B. A. ve Verbeek, J. H. A. M. (2015). A questionnaire to measure medical students' attitudes towards occupational medicine.Occupational Medicine, 65(1), 402-404.

Şenocak, M. (2014). Biyoistatistik ve araştırma yöntembilimi. İstanbul: Tıp Kitapevi.

Şimşek, Ö. F. (2007). Yapısal eşitlik modellemesine giriş: temel ilkeler ve LISREL uygulamalart. Ankara: Ekinoks Yayınc1lı.

Tabachnick, B. G. ve Fidel, S. L. (2001). Using multivariate statistics. New York: Harper Collin.

Tatlıdil, H. (1992). Uygulamalı çok değişkenli istatistiksel analiz. Ankara: Engin Yayınları.

Tavşancıl, E. (2006). Tutumların ölçülmesi ve spss ile veri analizi. Ankara: Nobel Yayın Dağıtım. 
Torun, N., Dinçer, M., Öztaş, D., Demir, P. ve Sanisoğlu, S. (2018). Tıp fakültesi öğrencilerinin hasta güvenliği kültürüne ilişkin tutum ölçeğinin Türkçe'ye uyarlanması. Journal of Contemporary Medicine, 8(2), 153-158, Doi: 10.16899/gopctd.424428.

Özcan, K., Bütün, İ. ve Gülcü, A. (2016). Mezuniyet öncesi tıbbi biyokimya eğitimine ilişkin tutum ölçeği geliştirme. Journal of Contemporary Medicine, 6(4), 291-299.

Y1lmaz, V. ve Çelik, H. E. (2009). LISREL ile yapısal eşitlik modellemesi: temel kavramlar, uygulamalar, programlama. Ankara: Pegem Akademi.

\section{Extended Abstract}

\section{Introduction}

Research has shown that it is possible for individuals to develop attitudes and to change these attitudes during the learning process. It is stated that individuals' attitudes towards the education they have taken and their attitudes towards the institutions they have educated may have positive or negative effects on their academic life (Gül, 2004). Alıc1 (2013) states that, in the education taken the academic success of a student who does not like the institution he/she is educated in, who does not like to go to classes, who hates, who exhibits the behavior of escaping classes is not expected to be the same with the one who likes to participate in classes, who enjoys taking classes and believes in the importance of education. The impact of these attitudes on the academic achievement of individuals becomes more evident in intensive and comprehensive trainings such as medical education. Considering that physician candidates spend a significant part of their professional life in medical faculties for education; their attitudes towards the education (medical education) they have taken here are important in terms of their academic achievements and the quality of the health services they would provide. Therefore, it is necessary to develop the affective characteristics of physician candidates in academic education as well as their academic success. Determining and eliminating the current problems of medical education and physician candidates, in order to increase the academic success of the students and the quality of the health services to be produced, is important to reveal the attitudes of physician candidates regarding the medical education and the elements of medical education in a reliable and valid manner. Therefore, in this study, it is aimed to develop a measurement tool in order to reveal the attitudes of physician candidates regarding to the medical education in a reliable and valid way.

\section{Method}

The data obtained in the extent of the study were obtained from a total of 552 students studying at Mersin University Medical Faculty.In order to determine the items to be included in the trial form of the scale; a literature search was done and the students were asked to write an essay about their feelings and thoughts about medical education.The literature review, the scales developed for similar purposes, and the data obtained from the essays written by the students were combined and a 65-item draft form, which is supposed to be a behavioral indicator of the attitudes of medical school students towards medical education, was formed. After review, the items found unsuitable for the purpose were removed from the form and a trial form of the scale was created through the remaining 41 items. Items included in the trial form are composed of 22 positive and 19 negative expressions.Each item in the form was scored with the help of the 5point Likert-type rating scale in the form of "Strongly Disagree", "Disagree", "Undecided", "Agree" and "Totally Agree". In the item analysis of the attitude scale for medical education, the relationship between item-total score was examined by Pearson correlation coefficient and after the analysis the items which's correlation were 0.20 and below were removed from the draft form (Tavşancil, 2006). In the next step, the factor structure of the scale was examined using exploratory factor analysis (EFA). Bartlett test and Kaiser-Meyer-Olkin (KMO) test results were taken into account for the suitability of the data for factor analysis (Tavşancil, 2006). The reliability of the scale was examined by Cronbach Alpha reliability coefficient. Confirmatory factor analysis (CFA) study was performed on the data obtained from different 
individuals in order to provide evidence for the validity of the structure determined by AFA and to reveal how much the observed structure was compatible with the data.The overall evaluation of the model in CFA was examined for Chi-Square Fit Test, Root Mean Square Error of Approximation (RMSEA), Comparative Compliance Index (CFI), Goodness of Fit Index (GFI), Adjusted Goodness of Fit Index (AGFI) and Root Mean Residual (RMR) (Kline, 2005). In addition, in order to provide additional evidence for the validity of the scale, the group mean difference between the lower $27 \%$ and the upper $27 \%$ of total scores was examined by independent groups $\mathrm{t}$ test.

\section{Result and Discussion}

After item analysis, the KMO value calculated for the suitability of the data for the scale test form consisting of 41 items was found to be 0.925 and the chi-square statistic calculated as the result of the Barlett test was significant (chi-square $=7258.59, \mathrm{p}<0.01$ ).

As a result of the EFA, 13 items were excluded in the scale, which were loading to more than one component, not under any component, and the communality values below 0.32 and EFA was repeated thru rest 28 items. After EFA and promax rotation, 6 components were found which's eigenvalue was more than 1.00 . The total variance explained by the only factor found and the 6 components was $62.237 \%$. The variance rate explained by each component was $36.342 \%, 7.035 \%, 5.715 \% 5,203 \%, 4,189 \%$ and $3,754 \%$ respectively.The calculated eigenvalues for each component were 10,176, 1,970, 1,600, 1,457, 1,173 and 1,051 respectively.Confirmatory factor analysis (CFA) study was performed on the data obtained from different individuals in order to provide evidence for the validity of the structure determined by AFA and to reveal how much the observed structure was compatible with the data. Compliance indices calculated by confirmatory factor analysis were obtained as RMSEA $=0.067$, CFI $=$ 0.97 , GFI $=0.84$, AGFI $=0.80, \mathrm{RMR}=0.069$. These values showed that the model fit was achieved.In order to provide additional evidence for the validity of the scale, it was examined whether there was a significant difference between the lower $27 \%$ and the upper $27 \%$ of the groups over the total scores, and the mean total score averages of the upper $27 \%$ of the group were observed as significantly higher than the mean total scores of the lower $27 \%$ of the group. (Upper Group $\bar{x}: 124.47 \pm 6.41$; Lower group $\bar{x}: 78,83 \pm 9,53 ; \mathrm{t}:-48,040 ; \mathrm{p}<0,001$ ). The alpha reliability for the whole scale was calculated as 0.933 . In addition, the alpha reliability values obtained for the subcomponents were $0.85 ; 0,76,0,81,0,82,0,80$ and 0,72 respectively.

From these results, it can be said that the scale reflects the attitudes of physician candidates towards medical education in a reliable and valid way. 